\title{
Avaliação da fosfatase alcalina óssea e hepática em gatos com tirotoxicose induzida
}

Fabiano Séllos COSTA ${ }^{1}$

Mauro José Lahm

CARDOSO $^{2}$

Lucy Marie Ribeiro MUNIZ ${ }^{3}$

Luiz Carlos VULCANO ${ }^{3}$

Paulo Roberto Rodrigues

RAMOS $^{4}$

Luís Antonio JUSTULIN

JUNIOR ${ }^{5}$

Sérgio Luís FELISBINO ${ }^{6}$

Warley Gomes dos

SANTOS $^{1}$

\section{Correspondência para:}

Fabiano Séllos Costa, Universidade Federal do Espírito Santo, Centro de Ciências Agrárias - Departamento de Medicina Veterinária, Alto Universitário $\mathrm{s} / \mathrm{n}$, fabianosellos@hotmail.com Alegre-ES, 29500-000

Recebido para publicação: 10/07/2006 Aprovado para publicação: 27/08/2009

\author{
1 - Departamento de Medicina Veterinária do Centro de Ciências Agrárias da \\ Universidade Federal do Espírito Santo, Alegre-ES \\ 2 - Fundação Faculdades Luiz Meneghel da Universidade Estadual do Paraná, \\ Bandeirantes-PR \\ 3 - Departamento de Reprodução Animal e Radiologia Veterinária da Faculdade de \\ Medicina Veterinária e Zootecnia da Universidade Estadual Paulista, Botucatu-SP \\ 4 - Departamento de Biofísica do Instituto de Biociências da Universidade Estadual \\ Paulista, Botucatu-SP \\ 5 - Departamento de Biologia Celular do Instituto de Biologia da Universidade \\ Estadual de Campinas, Campinas-SP \\ 6 - Departamento de Morfologia do Instituto de Biociências da Universidade \\ Estadual Paulista, Botucatu-SP
}

\section{Resumo}

A tirotoxicose é caracterizada pelas excessivas concentrações séricas dos hormônios tiroidianos, podendo desencadear graves alterações no metabolismo ósseo, sendo a elevação da fosfatase alcalina total uma alteração laboratorial freqüentemente observada no hipertiroidismo felino. $\mathrm{O}$ aumento global dos níveis séricos de fosfatase alcalina pode ser decorrente de diferentes isoenzimas e, no caso do hipertiroidismo em humanos, as isoenzimas de origem óssea e hepática apresentam-se comumente elevadas. A partir da avaliação da bioquímica sérica de oito gatos com tirotoxicose induzida e elevação da fosfatase alcalina associada, o presente trabalho demonstra um aumento significativamente maior dos níveis séricos da fosfatase alcalina de origem óssea quando comparado com a isoenzima de origem hepática. Conclui-se que as alterações no metabolismo ósseo foram as principais responsáveis pelo aumento da fosfatase alcalina nos gatos com tirotoxicose induzida.

\section{Introdução}

O hipertiroidismo felino é uma alteração clínica multissistêmica resultante das excessivas concentrações dos hormônios tiroidianos, sendo atualmente considerado o distúrbio endócrino de maior freqüência nos gatos domésticos. ${ }^{1,2,3,4}$

Estudos experimentais com indução a um estado de tirotoxicose foram desenvolvidos em cães, ${ }^{5}$ ratos, ${ }^{5,6,7}$ gatos $^{8,9} \mathrm{e}$ humanos, ${ }^{10,11}$ sendo possível demonstrar alterações no metabolismo ósseo, assim como ocorre no hipertiroidismo endógeno.

A reposição hormonal em excesso nas mulheres com hipotiroidismo, principalmente após a menopausa, pode produzir um estado hipermetabólico idêntico ao observado na tirotoxicose endógena, podendo ter como seqüela um remodelamento ósseo exagerado. ${ }^{12,13,14}$ Este fato assume destacada importância, uma vez que os hormônios da tiróide estão entre as medicações mais freqüentemente prescritas na medicina humana e a administração de uma dose acima da recomendada pode ocasionalmente ser encontrada. ${ }^{12}$

A elevação dos níveis séricos de fosfatase alcalina total (hiperfosfatasemia) é uma alteração laboratorial freqüente na ocorrência de hipertiroidismo no homem $2,3,4,15,16$ e nos felinos domésticos. 1,17,18,19,20,21 Segundo Peterson et al..$^{20}$, a partir da avaliação laboratorial 
de 131 gatos com hipertiroidismo, aproximadamente $75 \%$ dos animais apresentavam-se com hiperfosfatasemia ao momento do diagnóstico. São considerados valores normais para a espécie felina pelo método cinético níveis séricos de fosfatase alcalina total entre 25 e $93 \mathrm{U} / \mathrm{L}$, onde os valores acima do limite superior caracterizam a ocorrência de hiperfosfatasemia. ${ }^{22}$

Protocolos experimentais de indução ao estado de tirotoxicose também promoveram hiperfosfatasemia em ratas castradas $^{7}$ e gatos. ${ }^{8}$ Entretanto, os valores obtidos da avaliação bioquímica sérica desta enzima são resultantes da somatória das atividades das isoenzimas derivadas de diferentes tecidos do organismo, tais como fígado, osso, placenta, rins e intestino. . $^{1,23,4,13,14,15,16,18,23,24,25}$

$\mathrm{Na}$ ocorrência do hipertiroidismo felino, são descritas alterações no metabolismo ósseo e lesões hepáticas. A análise histopatológica do fígado de gatos com hipertiroidismo pode revelar aumento do pigmento dos hepatócitos, presença de células inflamatórias mistas em região portal e áreas focais de degeneração gordurosa. ${ }^{7}$ Entretanto, uma disfunção hepática é considerada rara na espécie humana e os achados histopatológicos observados são considerados discretos, inespecíficos e não apresentam correlação com a gravidade da doença. ${ }^{26}$

Outros trabalhos também em gatos demonstraram a ação hormonal sobre o tecido ósseo, promovendo significativa desmineralização, ${ }^{8}$ elevação dos níveis de osteocalcina $^{1}$, diminuição dos níveis de paratormônio e alterações no metabolismo de cálcio e fósforo. ${ }^{27}$

A caracterização e identificação das diferentes isoenzimas fornecem informações clínicas úteis para localizar o tecido responsável pela hiperfosfatasemia, podendo auxiliar no direcionamento do diagnóstico e no tratamento. ${ }^{4,16}$ Nos pacientes com hipertiroidismo, sejam humanos ${ }^{2,3,4,15,16}$ ou em felinos, ${ }^{1,18}$ a elevação da fosfatase alcalina total tem sido descrita como decorrente do aumento da atividade das isoenzimas de origem hepática e de origem óssea.

Além da avaliação da fosfatase alcalina total, as análises do perfil bioquímico sérico de enzimas que indicam lesão hepatocelular e colestase também podem auxiliar na diferenciação entre a ocorrência de alterações hepáticas ou ósseas. Valores de normalidade para a espécie felina das enzimas alanina aminotransferase (ALT), aspartato aminotransferase (AST) e gamaglutamil transferase (GGT) oscilam respectivamente entre 6 a $83 \mathrm{U} / \mathrm{L}, 26$ a $43 \mathrm{U} / \mathrm{L}$ e 1,3 a $5,1 \mathrm{U} / \mathrm{L} .{ }^{22}$

No presente estudo, foram avaliadas as isoenzimas de origem óssea e hepática em gatos domésticos induzidos à tirotoxicose experimental e que apresentaram alguma elevação da fosfatase alcalina, com o objetivo de melhor caracterizar a etiologia deste achado laboratorial nesta enfermidade.

\section{Material e Método}

Foram induzidos à tirotoxicose oito gatos domésticos (Felis catus, L. 1758), hígidos, adultos, sem distinção de sexo ou raça. Animais em fase de crescimento, idosos, castrados e fêmeas gestantes foram excluídos do grupo experimental. Os animais foram alojados em um gatil com acesso ao sol, sendo administrada alimentação (ração seca) e água à vontade. Após a realização do experimento, os gatos passaram por um período de desintoxicação de 10 dias para remissão dos sinais clínicos conforme sugerido por Costa. ${ }^{8}$ Posteriormente cada animal foi avaliado clinicamente e doados em seguida.

Para indução ao estado de tirotoxicose, administrou-se por via oral 150 $\mu \mathrm{g} / \mathrm{kg}$ de levotiroxina sódica a cada 24 horas durante 42 dias. Semanalmente os gatos eram pesados e as doses para cada animal eram reajustadas conforme a necessidade. Todos os dados experimentais foram colhidos imediatamente antes do início da administração do medicamento, sendo este considerado momento um (M1). Para efeito comparativo, posteriormente novas avaliações foram realizadas ao término do 
período experimental de 42 dias, sendo este considerado o momento dois (M2).

A dosagem dos níveis séricos dos hormônios tiroidianos [T4 livre (Coat a Count $^{\circledR}$ Total T4, Diagnostic Products Co., Los Angeles, Califórnia) e T4 total (Coat a Count ${ }^{\mathbb{B}}$ Free T4, Diagnostic Products Co., Los Angeles, Califórnia)] foram obtidas nos dois momentos, pela técnica de radioimunoensaio em fase sólida, utilizandose conjunto de reagente comercial sem qualquer tipo de extração química ou processo de purificação, tendo como elemento radioativo traçador o Iodo ${ }^{125}$. Todas as mensurações foram realizadas no Setor de Diagnóstico por Imagem da Faculdade de Medicina Veterinária e Zootecnia da UNESP, Campus de Botucatu.

Os níveis séricos de fosfatase alcalina total foram mensurados pelo método cinético, utilizando-se conjuntos de reagentes comerciais específicos (Cia. Equipadora de Laboratórios Modernos, Barueri, São Paulo). Para melhor avaliação bioquímica do perfil hepático do grupo experimental, mensuraram-se também os níveis plasmáticos das enzimas alanina aminotransferase (ALT), aspartato aminotransferase (AST) e gamaglutamil transferase (GGT) também por método cinético, sendo utilizado kits específicos para as dosagens enzimáticas.

A partir do sangue colhido dos animais do grupo experimental, confeccionou-se um "pool" de amostras séricas nos momentos inicial e final do experimento. Para a caracterização das isoenzimas da fosfatase alcalina, alíquotas com $4 \mu \mathrm{l}$ do "pool" das amostras foram submetidas à eletroforese sob condições não redutoras $\left(100 \mathrm{~V}\right.$ a $\left.4^{\circ} \mathrm{C}\right)$ em gel de poliacrilamida a $8 \%$. Posteriormente à eletroforese, os géis foram lavados com o tampão específico (Tris- $\mathrm{HCl} ; 0,1 \mathrm{M} \mathrm{NaCl}$; $0,005 \mathrm{M} \mathrm{MgCl}_{2}, \mathrm{pH}$ 9,5). Em seguida os géis foram corados após incubação por 12 horas a $37^{\circ} \mathrm{C}$ com o substrato específico BCIP (5bromo-4-cloro-3-indoilfosfato) associado ao corante NBT (nitroblue tetrazolium), possibilitando a coloração específica das isoenzimas da fosfatase alcalina. Para a quantificação da atividade das isoenzimas da fosfatase alcalina de origem hepática e óssea mensurou-se a densidade óptica integrada (IOD) das bandas de proteína presentes no gel de poliacrilamida após corados, utilizando-se o programa computacional Image Master VDS versão 3.0 acoplado ao aparelho Image Master VDS (Pharmacia Biotech).

Para a análise estatística das variações entre os momentos das variáveis fosfatase alcalina total, ALT, AST, GGT, T4 livre e T4 total, utilizou-se o teste "t de Student". Para a interpretação das letras, deve-se considerar que médias seguidas de uma mesma letra não diferem ao nível de 5\% de significância. Para a caracterização do comportamento das isoenzimas da fosfatase alcalina, realizou-se o teste de regressão destas variáveis entre os momentos inicial e final do protocolo experimental.

O presente trabalho foi aprovado pelo Comitê em Experimentação Animal da Faculdade de Medicina Veterinária e Zootecnia, UNESP, Botucatu, sob protocolo número 63/2002 - CEEA e está de acordo com os princípios éticos propostos pelo Colégio Brasileiro de Experimentação Animal.

\section{Resultados}

O protocolo utilizado para a indução ao hipertiroidismo, conforme previamente descrito na literatura ${ }^{8}$, promoveu uma elevação estatisticamente significativa dos níveis séricos de $\mathrm{T}_{4}$ livre e $\mathrm{T}_{4}$ total e conseqüente instalação de tirotoxicose no grupo experimental (Tabela 1).

Associada à tirotoxicose promovida é observada uma elevação significativa dos níveis séricos de fosfatase alcalina total após o início da administração hormonal nos 16 animais inicialmente utilizados no estudo $(p<0,01)$, entretanto, os valores médios não se apresentaram acima do limite máximo estabelecido para a espécie (Tabela 2).

Conforme demonstrado nas figuras 1 e 2, a análise das amostras séricas dos oito 
Tabela 1 - Valores séricos médios de T4 livre e T4 total e seus respectivos desvios padrões em oito gatos avaliados antes (M1) e após tirotoxicose induzida (M2) - Botucatu - 2006

\begin{tabular}{ccc}
\hline Variável & M1 & M2 \\
\hline T4 Livre $(\mathrm{ng} / \mathrm{dL})$ & $0,47^{\mathrm{a}} \pm 0,27$ & $1,09^{\mathrm{b}} \pm 0,69$ \\
T4 total $(\mu \mathrm{g} / \mathrm{dL})$ & $2,84^{\mathrm{a}} \pm 1,81$ & $9,10^{\mathrm{b}} \pm 4,17$ \\
\hline
\end{tabular}

M1 - momento inicial, M2 - momento final; Médias seguidas de letras iguais na mesma linha não diferem ao nível de $5 \%$ de significância pelo teste " $t$ de Student".

Tabela 2 - Valores bioquímicos séricos médios e seus respectivos desvios padrões para avaliação do perfil hepático em oito gatos avaliados antes (M1) e após tirotoxicose induzida (M2) - Botucatu - 2006

\begin{tabular}{lcc}
\hline Variável & M1 & M2 \\
\hline FA (U/L) & $38^{a} \pm 19$ & $83^{\mathrm{b}} \pm 41$ \\
ALT (U/L) & $66^{\mathrm{a}} \pm 16$ & $72^{\mathrm{a}} \pm 23$ \\
AST (U/L) & $28^{\mathrm{a}} \pm 8$ & $32^{\mathrm{a}} \pm 7$ \\
GGT (U/L) & $0,12^{\mathrm{a}} \pm 0.3$ & $0,30^{\mathrm{a}} \pm 1,0$ \\
\hline
\end{tabular}

Médias seguidas de letras iguais na mesma linha não diferem ao nível de $5 \%$ de significância pelo teste "t de Student".

FA - fosfatase alcalina total, ALT - alanina aminotransferase, AST - aspartato aminotransferase, GGT - gama glutamiltransferase, M1 - momento inicial, M2 momento final.

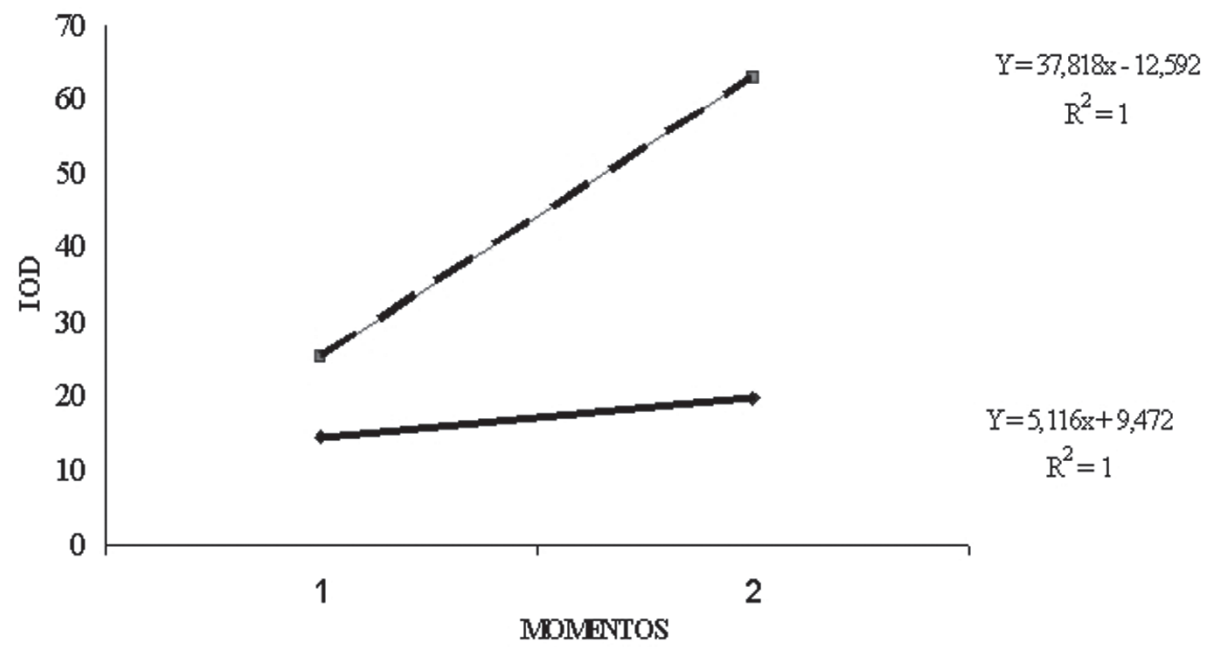

Figura 1 - Análise de regressão dos valores de fosfatase alcalina óssea (linha descontínua) e hepática (linha contínua) em gatos com tiroxicose induzida

animais com maior amplitude de variação dos valores de fosfatase alcalina total revelou que a isoenzima de origem óssea apresentou marcante aumento entre os momentos inicial e final. A fosfatase alcalina de origem hepática apresentou-se aumentada em menor magnitude ao final do experimento, não havendo significância estatística.

A avaliação bioquímica sérica das enzimas ALT, AST e GGT destes oito animais selecionados não revelou alterações significativas entre os momentos estudados e os valores médios permaneceram dentro dos padrões de normalidade para felinos domésticos $(\mathrm{p}>0,05)$ (Tabela 2$)$. 


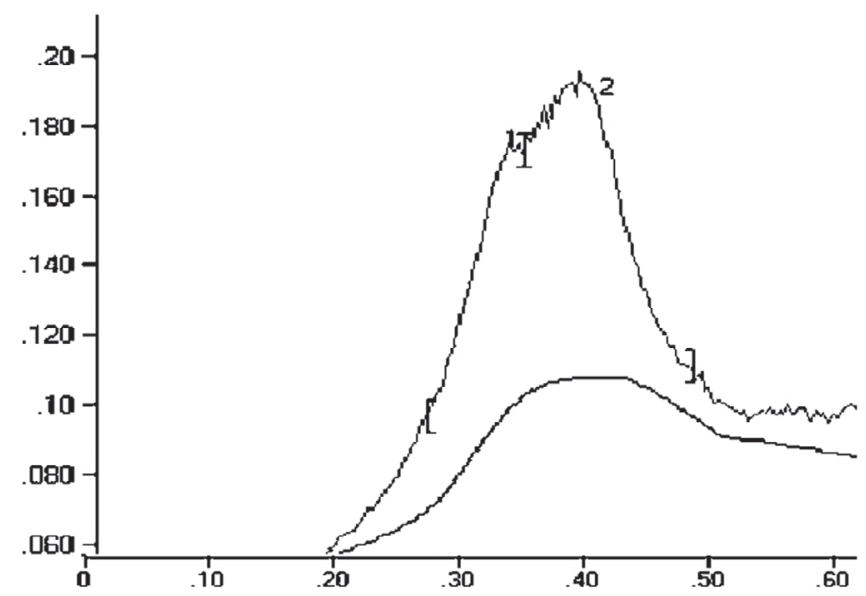

Figura 2 - Representação gráfica demonstrando a densidade óptica integrada após eletroforese das isoenzimas de origem hepática (1) e óssea (2) em gatos com tiroxicose induzida

\section{Discussão e Conclusões}

Como nesta pesquisa, outros autores também conseguiram promover uma tirotoxicose exógena a partir da administração oral de levotiroxina sódica, ${ }^{5,6,7,8,10,11}$ comprovando que os protocolos de indução podem servir como ensaios experimentais para melhor caracterização da doença clínica. As semelhanças nas alterações no tecido ósseo e níveis séricos de fosfatase alcalina total na tirotoxicose de origem exógena e endógena em humanos, conforme previamente descrito em mulheres submetidas a uma reposição hormonal excessiva, ${ }^{12}$ levam a considerar que fato semelhante ocorra nos gatos domésticos. Dessa forma, possivelmente a fisiopatologia da hiperfosfatasemia em ambos os casos seja similar.

Apesar do período de administração hormonal ter sido apenas de 42 dias, já foi possível caracterizar uma alteração estatisticamente significativa dos níveis séricos de fosfatase alcalina total. Dessa forma, assim como na tirotoxicose endógena, uma elevação dos níveis séricos de fosfatase alcalina total foi uma alteração laboratorial comumente observada. ${ }^{17,19,20,21}$ As alterações metabólicas secundárias à administração experimental excessiva de hormônios tiroidianos também ocorreram rapidamente em estudos experimentais em cães, ${ }^{10}$ ratos, ${ }^{5,6,7}$ felinos domésticos ${ }^{8}$ e humanos ${ }^{1}$.

A ausência de alterações nos níveis plasmáticos das enzimas ALT, AST e GGT, associada à discreta e não significativa elevação da atividade da isoenzima da fosfatase alcalina de origem hepática demonstra sua pequena contribuição para a hiperfosfatasemia observada na tirotoxicose experimental em gatos. Tal fato concorda com demais trabalhos em humanos com tirotoxicose, que observaram discretas alterações histopatológicas no parênquima hepático ${ }^{26}$ e uma maior atividade da isoenzima da FA originária do tecido ósseo. ${ }^{2,4,15,16}$

No hipertiroidismo felino de origem endógena, estudos retrospectivos ${ }^{17}$ demonstram uma alta freqüência de gatos com aumento de atividade das enzimas ALT e AST, estando estes achados laboratoriais presentes em aproximadamente 54\% dos animais acometidos por esta enfermidade. Fatores como a coexistência de outras alterações hepáticas e um maior tempo de submissão ao estado de tirotoxicose nos gatos com a doença clínica, levando ao aparecimento de lesões tardias no parênquima hepático, podem, possivelmente, contribuir para a presença destes achados laboratoriais. 
O comportamento da fosfatase alcalina nos gatos apresenta algumas particularidades quando comparado com cães e essas diferenças devem ser consideradas para a interpretação laboratorial das variações observadas nesta enzima. De acordo com a literatura, ${ }^{22}$ a atividade normal da isoenzima de origem hepática de gatos é muito menor que de cães e, adicionalmente, a meia-vida da FA total circulante nos gatos é significativamente mais curta que em cães.

Pesquisas desenvolvidas em gatos com hipertiroidismo endógeno demonstram também uma elevação das isoenzimas de origem hepática contribuindo para a hiperfosfatasemia. Nesta pesquisa, a variação da FA hepática não foi significativa entre os momentos avaliados, sendo a FA óssea a principal responsável pelo aumento sérico da fosfatase alcalina total. Este acontecimento também já foi previamente observado por outros autores na espécie humana..$^{2,3,4,15,16}$ Entretanto, deve-se considerar que o presente experimento promoveu um quadro de tirotoxicose agudo, no período de 42 dias de tratamento com levotiroxina sódica. É possível que uma tirotoxicose de caráter crônico, assim como observado na maioria dos casos diagnosticados da doença clínica em gatos, seja capaz de desencadear maiores injúrias ao fígado e conseqüentemente uma elevação mais significativa da isoenzima de origem hepática.

Gatos idosos apresentam maior freqüência de hipertiroidismo, sendo observado que uma porcentagem inferior a $5 \%$ dos gatos apresenta-se com menos de 10 anos de idade ao momento do diagnóstico. ${ }^{19} \mathrm{Na}$ espécie humana a faixa etária do paciente é considerada um fator importante para a interpretação dos valores de fosfatase alcalina total, onde há uma elevação fisiológica dos níveis séricos de FA hepática em pessoas idosas. ${ }^{3}$ Este fato observado em humanos parece estar correlacionado com a discreta alteração da FA de origem hepática observada no presente trabalho em gatos domésticos, uma vez que os animais utilizados no experimento eram em sua totalidade adultos jovens.

Conclui-se desta forma que a isoenzima da fosfatase alcalina de origem óssea foi a principal responsável pela ocorrência da de um aumento dos níveis séricos de fosfatase alcalina total nos gatos submetidos à tirotoxicose experimental. $\mathrm{O}$ trabalho realizado possibilitou caracterizar a influência hormonal sobre os níveis séricos de fosfatase alcalina total e de suas isoenzimas, contribuindo para melhor caracterizar a etiologia da hiperfosfatasemia no hipertiroidismo felino.

\section{Agradecimentos}

À FAPESP, pelo suporte financeiro.

\section{Evaluation of bone and liver alkaline phosphatase in cats with induced thyrotoxicosis}

\begin{abstract}
Thyrotoxicosis, characterized by excessive serum levels of thyroid hormones, can cause serious effects in bone metabolism, elevating the total alkaline phosphatase, which is a frequent laboratorial alteration observed in feline hyperthyroidism. A rise in total serum levels of alkaline phosphatase can be caused by different isoenzymes, and in human hyperthyroidism, bone and hepatic isoenzymes are commonly increased. After serum biochemical evaluation of eight cats with induced thyrotoxicosis and associated elevation of alkaline phosphatase, the present paper shows a significant elevation of bone isoenzyme serum levels when compared with hepatic isoenzyme. It
\end{abstract}

Key words:

Alkaline phosphatase. Isoenzyme. Hyperthyroidism. Cat. 
was possible to conclude that bone metabolism alterations were the main responsible for the increase of serum alkaline phosphatase in cats with induced thyrotoxicosis.

\section{Referências}

1 ARCHER F. J.; TAYLOR S. M. Alkaline phosphatase bone isoenzyme and osteocalcin in the serum of hyperthyroid cats. Canadian Veterinary Journal, v. 37, n.12, p. 735-739, 1986.

2 COOPER, D. S.; KAPLAN, M. M.; RIDGWAY, E. C.; MALOOF, F.; DANIELS, G. H. Alkaline phosphatase isoenzyme patterns in hyperthyroidism. Annals of Internal Medicine, v. 90, n.2, p. 164-168, 1979.

3 MOSS, D. W. Alkaline phosphatase isoenzyme. Clinical Chemistry, v. 28, p. 2007-2016, 1982.

4 TIBI, L.; PATRICK, A. N.; LESLIE, P.; TOFT, A. D.; SMITH, A. F. Alkaline phosphatase isoenzymes in plasma in hyperthyroidism. Clinical Chemistry, v. 35, p. 427-430, 1989.

5 KUNG, A. W.; NG, F. A rat model of thyroid hormone-induced bone loss: effect of antiresorptive agents on regional bone density and osteocalcin gene expression. Thyroid, v. 4, n. 1, p. 93-98, 1994.

6 PEREIRA, R. C.; JORGETTI, V.; CANALIS, E. Triiodothyronine induces collagenase- 3 and gelatinase B expression in murine osteeoblasts. American Journal of Physiology - Endocrinology and Metabolism, v. 277, n.3, p. E496-E504, 1999.

7 SERAKIDES, R.; NUNES, V. A.; NASCIMENTO, E. F.; SILVA, C. M.; RIBEIRO, A. C. F. Relação tireóidegônadas e níveis plasmáticos de fósforo, cálcio e fosfatase alcalina em ratas. Arquivos Brasileiros de Medicina Veterinária e Zootecnia, v. 52, n.6, p. 579585, 2000.

8 COSTA, F. S. Tirotoxicose experimental em gatos: efeitos sobre o tecido ósseo, níveis séricos de fosfatase alcalina e metabolismo de cálcio e fósforo. 2002. 98 f. Dissertação (Mestrado) - Faculdade de Medicina Veterinária e Zootecnia, Universidade Estadual Paulista, Botucatu, 2002.

9 FELDMAN, E. C.; NELSON, R. W. Canine and feline endocrinology and reproduction. Philadelphia: WB Saunders, 1996. 785 p.

10 ADAMS, P.; JOWSEY, J. Bone and mineral metabolism in hyperthyroidism: an experimental study. Endocrinology, v. 81, n. 4, p. 735-740, 1967.

11 LUKENSMEYER, W. W.; HEGE, J. H.; THEIL, G. B.; WILSON, W. R. Calcium and phosphorus metabolic studies in triiodothyronine-induced hypermetabolism. The American Journal of the Medical Science, v. 259, p. 282-291, 1970.

12 FALLON, M. D.; PERRY, H. M.; BERGFELD, M.; DROKE, D.; TEITELBAUM, S. L.; AVIOLI, L. V.;
Exogenous hyperthyroidism with osteoporosis. Archives of Internal Medicine, v. 143, n. 3, p. 442-444, 1983.

13 FOLDES, J.; TARJAN, G.; SZATHMARI, M.; KRASZNAI, I.; HORVATH, C. Bone mineral density in patients with endogenous subclinical hyperthyroidism: is this thyroid status a risk factor for osteoporosis? Clinical Endocrinology, v. 39, n. 5, p. 521-527, 1993.

14 JODAR, E.; TORRES, M. M.; JIMÉNES, F. E.; CHARNECO, M. Q.; CASTILLO, J. D. L. Bone loss in hyperthyroid patients and in former hyperthyroid patients controlled on medical therapy: influence of etiology and menopause. Clinical Endocrinology, v. 47 n. 3, p. 279-285, 1997.

15 GERLACH, U.; PAUL, L.; LATZEL, H. Isoenzymes of alkaline phosphatase in hyperthyroidism. Enzymologia Biologica et Clinica, v. 11, n. 3, p. 251-256, 1970.

16 HORNEY, B. S.; FARMER, A. J.; MACKENSIE, A.; HONOR, D. J.; BUCZKOWSKI, S. Alkaline phosphatase isoenzymes in feline serum using an agarose gel alkaline phosphatase kit method. Canadian Journal of Veterinary Research, v. 56, n. 4, p. 373-375, 1992.

17 BROUSSARD, J. D.; PETERSON, M. E.; FOX, P. R. Changes in clinical and laboratory findings in cats with hyperthyroidism from 1983 to 1993. Journal of the American Veterinary Medical Association, v. 206, n. 3, p. 302-305, 1995.

18 FOSTER, D. J.; THODAY, K. L. Tissue sources of serum alkaline phosphatase in 34 hyperthyroid cats: a qualitative and quantitative study. Research in Veterinary Science, v. 68, n.1, p. 89-94, 2000.

19 MOONEY, C. T. Hyperthyroidism. In: ETTINGER S. J.; FELDMAN, E. C. Textbook of veterinary internal medicine. 6.ed. St. Louis: Elsevier Saunders, 2005. p. 1544-1560.

20 PETERSON, M. E.; KINTZER, P. P.; CAVANAGH, P. G.; FOX, P. R.; FERGUSON, D. C.; JOHNSON, G. F.; BECKER, D. V. Feline hyperthyroidism: pretreatment clinical and laboratory evaluation of 131 cases. Journal of the American Veterinary Medical Association, v. 183, n. 1, p. 103-110, 1983.

21 THODAY, K. L.; MOONEY, C. T. Historical, clinical and laboratory features of 126 hyperthyroid cats Veterinary Records, v. 131, n. 12, p. 257-264, 1992.

22 KANEKO, J. J.; HARVEY, J. W.; BRUSS, M. L. Clinical biochemistry of domestic animals. San Diego: Academic Press, 1997. 932 p.

23 EVERETT, R. M.; DUNCAN, J. R.; PRASSE, K. W. Alkaline phosphatases in tissues and sera of cats American Journal of Veterinary Research, v. 38, n. 10, p. 1533-1538, 1997

24 HOFFMANN, W. E.; RENEGAR, W. E.; DORNER, 
J. L. Serum half-life of intravenously intestinal and hepatic alkaline phosphatase isoenzymes in the cat. American Journal of Veterinary Research, v. 38, n. 10, p. 1637-1639, 1977.

25 RHONE, D. P.; BERLINGER, F. G.; WHITE, F. M. Tissue sources of elevated serum alkaline phosphatase activity in hyperthyroid patients. American Journal of Clinical Pathology, v. 74, n. 4, p. 381-386, 1980.

26 KLION, F. M.; SEGAL, R.; SCHAFFNER, F. The effect of altered thyroid function on the ultrastructure of the human liver. American Journal of Medicine, v. 50, n. 3, p. 317-324, 1971.

27 BARBER, P. J.; ELLIOT, J. Study of calcium homeostasis in feline hyperthyroidism. Journal of Small Animal Practice, v. 37, n. 12, p. 575-582, 1996. 